DR. OLGA GORLANOVA (Orcid ID : 0000-0002-3153-7404)

PROF. MICHAEL KABESCH (Orcid ID : 0000-0003-0697-1871)

Article type : Letter to the Editor

Handling AE: Cezmi Akdis

\title{
Protective effects of breastfeeding on respiratory symptoms in infants with 17q21
}

\section{asthma risk variants}

\section{To the Editor:}

Genetic polymorphisms at the 17q21 locus have been associated with the subsequent onset of childhood asthma and appear to strengthen the association between childhood asthma and early episodes of wheezing.(1,2) A recent study of Loss et al.(2) showed that 17q21 alleles modified the effect of exposure to older siblings and animal shed on episodes of wheeze in infancy. Since environmental factors seem to play a role with respect to the effect modification by the 17q21 polymorphism, our aim was to assess whether the association between asthma-associated $17 \mathrm{q} 21$ variants, and lower respiratory symptoms during the $1^{\text {st }}$ year of life, may be modified by breastfeeding. In addition, we investigated whether the described interactions with other environmental exposures, such as older siblings(2) and tobacco exposure, $(3,4)$ were reproducible.

We tested our hypothesis within the prospective Basel-Bern Infant Lung Development (BILD) birth cohort of healthy unselected infants ( $\mathrm{n}=368$ ) living in urban environments.(5) Parental written informed consent was obtained and the study was approved by the ethics committees of Basel and Bern. Respiratory symptoms, such as occurrence of cough, wheeze or difficulty breathing during the night and day - and their severity -were assessed by weekly This article has been accepted for publication and undergone full peer review but has not been through the copyediting, typesetting, pagination and proofreading process, which may lead to differences between this version and the Version of Record. Please cite this article as doi: $10.1111 /$ all.13568

This article is protected by copyright. All rights reserved. 
telephone interviews using a standardized symptom score (each on a scale of $0-4$, with 0 indicating no symptoms and $\geq 3$ severe symptoms).(5) As a primary outcome, the respiratory symptoms score was calculated as a sum total of daytime and nighttime symptoms scores (on a scale of 0-8).(5) The secondary outcome was episodes of wheeze in the $1^{\text {st }}$ year of life that were defined as a whistling sound in the chest audible to the parents, or doctor-diagnosed wheeze. Wheeze episodes have been recorded since 2004 on a weekly basis (based on a "yes or no" question); therefore, we restricted our sample to those infants with complete information on wheeze $(\mathrm{n}=252)$.

Genome-wide genotyping was performed using Illumina HumanOmniExpress Bead Chips (Illumina Inc., San Diego, USA). Five major tagging SNPs at the locus 17q21: rs7216389, rs4795405, rs8079416, rs8065126 and rs3902025 were included in the analysis. These variants were selected as representative of the five highest asthma-associated tagging bins based on unpublished 17q21 fine mapping data (1,446 children, 763 asthmatics, from the German MAGIC and ISAAC II studies), presented at the $11^{\text {th }}$ Meeting of the European Human Genetics Societies. For the purposes of our study, either the major tagging SNP from the respective bin was analyzed (rs3902025), or a proxy in high linkage disequilibrium.

Generalized additive mixed model with quasi Poisson and Binomial distribution for count and binary outcomes was used to investigate weekly measured respiratory symptom scores and any breastfeeding ( "yes or no" for each week under observation). We applied autoregressive AR(1) modeling to account for inter-child variation. Each SNP was coded as $0 / 1 / 2$ for the number of risk alleles and analyzed separately under the additive model. The interaction was tested by adding to the adjusted model the multiplicative interaction term between breastfeeding and SNP.

This article is protected by copyright. All rights reserved. 
Next we attempted a replication of top SNPs within the Protection against Allergy Study in Rural Environments (PASTURE) birth cohort study $(n=799)$ that was conducted in rural areas. Information on respiratory symptoms (defined as the presence of wheeze or cough) and any breastfeeding was collected from weekly and 4-weekly diaries. We used a stringent Bonferroni $P$-value correction threshold of $0.01(0.05 / 5)$ and $0.025(0.05 / 2)$ for discovery and replication analysis, respectively. Further information on demographic (eTable 1) and genotype characteristics, methods and meta-analyses of both cohorts are provided in the Supplement.

The $17 \mathrm{q} 21$ SNPs were not associated with respiratory symptoms score during the $1^{\text {st }}$ year of life. When we stratified infants by breastfeeding status, we found that, during those weeks when infants were breastfed, the carriers of asthma risk alleles of the most strongly associated SNPs (rs7216389-T and rs4795405-C, Table 1) were more responsive to the protective effect of breastfeeding on respiratory symptoms. In contrast, during those weeks when infants were not breastfed, the same genotype showed a trend towards an increased risk for respiratory symptoms, resulting in a significant interaction effect for both SNPs ( $P$ for interaction 0.0006 and 0.0041 , respectively, Table 1). Though the direction of the association in the entire wheeze subset of infants, and across strata by breastfeeding, was the same as in the main analysis, no significant interaction was observed between the $17 \mathrm{q} 21$ locus and breastfeeding in relation to wheeze that may be explained by limited power and conservative correction for multiple comparisons.

In the PASTURE cohort, the protective effect of breastfeeding on wheeze was present only in carriers of asthma risk alleles of rs8076131 (the closest proxy of rs4795405, $\mathrm{r}^{2}=0.92 ; \mathrm{r}^{2}$-value is based on a study by Toncheva et al (6)) (Figure 1). Similar effects were observed in carriers of risk alleles of rs4795405 in relation to wheeze in the BILD cohort. However, we found no evidence for an interaction. The meta-analysis of interaction effects in the BILD 
and PASTURE data yield a borderline significant effect for rs4795405 ( $P$-value $=0.028$, eFigure 1 in the Supplement). Factors that may weaken the breastfeeding interaction in the PASTURE cohort were population specific genetic and environmental factors, such as high farm exposure and an interaction of breastfeeding status with farming exposure in relation to respiratory symptoms (data not shown). We hypothesize that the influence of the 17q21 locus on respiratory symptoms may be modified by multiple environmental factors, and their relative small size impact may depend on the environmental context.

In accordance with Loss et al.(2), we were able to replicate the interaction between the 17q21 locus and the presence of older siblings. Consistent with other studies(2, 3), we did not find interaction with maternal smoking during pregnancy (eTable 2 in the Supplement).

There are several interpretations we can consider on the interaction between 17q21 SNPs and breastfeeding in relation to respiratory symptoms. First, breast milk is rich in immune components inhibiting virus replication, regulating mucosal immunity(7), and shifting the gut microbiota towards species which strengthen the immune response.(8) Secondly, the 17q21 locus may increase susceptibility to viral infection.(1) Thirdly, DNA methylation in CpG cites of rs7216389 and rs4795405 was associated with mRNA expression of Orosomucoid like 3 (ORMDL3) gene.(9) This would make carriers of the asthma risk genotype potentially more responsive to the protective effect of breastfeeding. Finally, epigenetic phenomena are known to be related to $17 \mathrm{q} 21 .(10)$

In conclusion, our findings demonstrated evidence suggestive of interaction between $17 \mathrm{q} 21$ variants and breastfeeding in relation to respiratory symptoms in the $1^{\text {st }}$ year of life. Infants with the asthma risk allele might particularly profit from the protective effect of breastfeeding on early-life respiratory infection, which is an important target for secondary asthma prevention. Since multiple exposures seem to affect 17q21 in a complex manner, observed 
gene-environment interactions may be specific for a given environment (e.g. rural versus urban context).

\section{References}

1. Çalışkan M, Bochkov YA, Kreiner-Møller E, Bønnelykke K, Stein MM, Du G, et al. Rhinovirus Wheezing Illness and Genetic Risk of Childhood-Onset Asthma. New England Journal of Medicine 2013;368(15):1398-1407.

2. Loss GJ, Depner M, Hose AJ, Genuneit J, Karvonen AM, Hyvärinen A, et al. The early development of wheeze. Environmental determinants and genetic susceptibility at $17 q 21$. American journal of respiratory and critical care medicine 2016;193(8):889-897.

3. Brauner EV, Loft S, Raaschou-Nielsen O, Vogel U, Andersen PS, Sorensen M. Effects of a 17 q21 chromosome gene variant, tobacco smoke and furred pets on infant wheeze. Genes Immun 2012;13(1):94-97.

4. Bouzigon E, Corda E, Aschard H, Dizier M-H, Boland A, Bousquet J, et al. Effect of 17q21 variants and smoking exposure in early-onset asthma. New England Journal of Medicine 2008;359(19):1985-1994.

5. Gorlanova O, Thalmann S, Proietti E, Stern G, Latzin P, Kühni C, et al. Effects of breastfeeding on respiratory symptoms in infancy. The Journal of pediatrics 2016;174:111-117. e115.

6. Toncheva A, Potaczek D, Schedel M, Gersting S, Michel S, Krajnov N, et al. Childhood asthma is associated with mutations and gene expression differences of ORMDL genes that can interact. Allergy 2015;70(10):1288-1299.

7. Oddy WH. A review of the effects of breastfeeding on respiratory infections, atopy, and childhood asthma. Journal of Asthma 2004;41(6):605-621.

8. Fernández L, Langa S, Martín V, Maldonado A, Jiménez E, Martín R, et al. The human milk microbiota: origin and potential roles in health and disease. Pharmacological Research 2013;69(1):110.

9. Acevedo N, Reinius LE, Greco D, Gref A, Orsmark-Pietras C, Persson H, et al. Risk of childhood asthma is associated with CpG-site polymorphisms, regional DNA methylation and mRNA levels at the GSDMB/ORMDL3 locus. Human molecular genetics 2015;24(3):875-890.

10. Hartwig FP, de Mola CL, Davies NM, Victora CG, Relton CL. Breastfeeding effects on DNA methylation in the offspring: A systematic literature review. PloS one 2017;12(3):e0173070.

This article is protected by copyright. All rights reserved. 


\section{Author Information}

Olga Gorlanova, $\mathrm{MD}^{1}$; Sabina Illi, $\mathrm{PhD}^{2}$; Antoaneta A. Toncheva, $\mathrm{PhD}^{3}$; Jakob Usemann, MD, $\mathrm{PhD}^{1,4}$; Philipp Latzin, $\mathrm{MD}, \mathrm{PhD}^{4}$; Michael Kabesch, $\mathrm{MD}, \mathrm{PhD}^{3}$; Jean-Charles Dalphin, $\mathrm{MD}, \mathrm{PhD}^{5}$; Roger Lauener, $\mathrm{MD}, \mathrm{PhD}^{6,7}$; Juha R. Pekkanen, $\mathrm{PhD}^{8,9}$; Erika Von Mutius, MD, $\mathrm{PhD}^{2}$; Josef Riedler, $\mathrm{MD}, \mathrm{PhD}^{10}$; Claudia Kuehni, $\mathrm{MD}, \mathrm{PhD}^{11}$; Martin Röösli, $\mathrm{PhD}^{12}$; Urs Frey, $\mathrm{MD}, \mathrm{PhD}^{1}$ on behalf of the BILD and PASTURE study groups

${ }^{1}$ University Children's Hospital (UKBB), University of Basel, Basel, Switzerland

${ }^{2}$ Dr von Hauner Children’s Hospital, Ludwig Maximilian University, Munich, Germany, Comprehensive Pneumology Center Munich (CPC-M), Member of the German Center for Lung Research

${ }^{3}$ Department of Pediatric Pneumology and Allergy, University Children's Hospital Regensburg (KUNO), Regensburg, Germany

${ }^{4}$ Division of Respiratory Medicine, Department of Paediatrics, Inselspital, Bern University Hospital, University of Bern, Switzerland

${ }^{5}$ University of Besançon, Department of Respiratory Disease, UMR/CNRS 6249 Chronoenvironment, University Hospital, Besançon, France

${ }^{6}$ Children's Hospital of Eastern Switzerland, St. Gallen, Switzerland

${ }^{7}$ Christine Kühne Center for Allergy Research and Education (CK-CARE), Davos, Switzerland

${ }^{8}$ National Institute for Health and Welfare, Kuopio, Finland

${ }^{9}$ Department of Public Health, University of Helsinki, Finland 
${ }^{10}$ Children's Hospital Schwarzach, Teaching Hospital Paracelsus Private Medical University Salzburg, Austria

${ }^{11}$ Institute for Social and Preventive Medicine, University of Bern, Switzerland

${ }^{12}$ Swiss Tropical and Public Health Institute Basel, Basel, Switzerland

Corresponding author: Olga Gorlanova, MD, University Children's Hospital (UKBB), Spitalstrasse 33, 4056 Basel, Switzerland (olga.gorlanova@ukbb.ch).

Author Contributions: Drs Gorlanova and Illi had full access to all the data in the study and take responsibility for the integrity of the data and the accuracy of the data analysis.

Study concept and design: Urs Frey, Olga Gorlanova, Sabina Illi, Michael Kabesch, Philipp Latzin, Erika von Mutius, and Antoaneta A. Toncheva.

Acquisition, analysis, or interpretation of data: All authors.

Drafting of the manuscript: Olga Gorlanova, Urs Frey.

Critical revision of the manuscript for important intellectual content: All authors.

Statistical analysis: Olga Gorlanova, Sabina Illi.

Obtained funding: Urs Frey

Study supervision: Urs Frey, Olga Gorlanova.

Conflicts of Interest: Dr. von Mutius reports holding grants from the European Commission, the European Research Council and the German Research Foundation, during the conduct of the study. Dr. von Mutius has also recieved personal fees from the following organizations 
for her contribution outside the context of the submitted work: the American Academy of Allergy, Asthma \& Immunology, the Ökosoziales Forum Oberösterreich, Mundipharma, HAL Allergie GmbH, from DOC Congress SRL, American Thoracic Society, University of Tampere; GBS RE HEFCE, Novartis Pharma, OM Pharma SA, AbbVie Deutschland GmbH \& Co. KG, medUpdate GmbH, and System Analytic Ltd.

Dr. Latzin reports personal fees from OM Pharma SA, Roche, Vertex and Gilead, all outside of the submitted work.

Dr. Frey reports a personal fee from a GSK scientific board meeting 2016, outside of the submitted work.

Dr. Pekkanen reports holding grants from the European Commission and Academy of Finland during the conduct of the study.

Dr. Lauener reports holding grants from the Kühne Foundation / Christine Kühne-Center for Allergy Research and Education, the European Union and the Swiss National Research Foundation during the conduct of the study. Dr. Lauener has received fees and/or served on advisory boards from Menarini, Meda, Nestlé, AstraZeneca, the Pfizer Research Prize Foundation, Vifor and the Swiss Government, all outside of the submitted work.

Dr. Kabesch reports holding grants from the European Union, German Ministry of Education and Research, German Research Foundation during the conduct of the study. Dr. Kabesch reports a personal fees from Bionorica, ERS, EAACI, ATS, Novartis, Glaxo, Nutricia, and Hipp, all outside of the submitted work.

This article is protected by copyright. All rights reserved. 
Funding/Support: This work was supported by the Swiss National Science Foundation (Schweizerischer Nationalfonds zur Förderung der Wissenschaftlichen Forschung) (grant no. 320030_163311,32003B-144068, and 32003B_162820).

Role of the Funder: The funding sources had no role in the design and conduct of the study; collection, management, analysis, and interpretation of the data; preparation, review, or approval of the manuscript; and or the decision to submit the manuscript for publication.

Group Information: The Basel Bern Infant Lung Development (BILD) cohort was part of the collaboration responsible for this work. Its current members are (in alphabetical order): Pinelopi Anagnostopoulou, MD (Bern University Hospital, Bern); Urs Frey, PhD (University of Basel Children's Hospital, Basel); Oliver Fuchs, PhD (Bern University Hospital, Bern); Olga Gorlanova, MD (University of Basel Children's Hospital, Basel); Insa Korten, PhD (Bern University Hospital, Bern); Philipp Latzin, PhD (Bern University Hospital); Loretta Müller, PhD (University of Basel Children's Hospital, Basel); Elena Proietti, PhD (University of Zurich Children's Hospital, Zurich); Anne Schmidt, PhD ((University of Basel Children's Hospital, Basel); Jakob Usemann, PhD (University of Basel Children's Hospital, Basel). The Protection against Allergy Study in Rural Environments (PASTURE) cohort, current study group (in alphabetical order by study center):

Finland: Anne Hyvärinen, PhD (National Institute for Health and Welfare, Kuopio); Anne Karvonen, PhD, (National Institute for Health and Welfare, Kuopio); Pirkka Kirjavainen, $\mathrm{PhD}$, (National Institute for Health and Welfare, Kuopio); Sami Remes, MSc, (National 
Institute for Health and Welfare, Kuopio); Marjut Roponen, $\mathrm{PhD}$, (National Institute for Health and Welfare, Kuopio).

France: Amandine Chauveau, PhD, (University Hospital of Besançon, Besançon); MarieLaure Dalphin, PhD, (University Hospital of Besançon, Besançon); Vincent Kaulek, PhD, (University Hospital of Besançon, Besançon);

Germany: Martin Depner, PhD, (Dr von Hauner Children's Hospital, Ludwig Maximilian University, Munich); Markus Ege, MD, (Comprehensive Pneumology Center Munich, Member of the German Center for Lung Research, Munich); Jon Genuneit, MD, (Ulm University, Ulm); Georg Loss, $\mathrm{PhD}$, (Dr von Hauner Children's Hospital, Ludwig Maximilian University, Munich); Petra Pfefferle; $\mathrm{PhD}$, (Institute for Laboratory Medicine and Pathobiochemistry, Molecular Diagnostics, Philipps University of Marburg, Marburg); Harald Renz, PhD, (Institute for Laboratory Medicine and Pathobiochemistry, Molecular Diagnostics, Philipps University of Marburg, Marburg); Bianca Schaub, MD, (Comprehensive Pneumology Center Munich, Member of the German Center for Lung Research, Munich);

Switzerland: Charlotte Braun-Fahrländer, MD, (Swiss Tropical and Public Health Institute, University of Basel, Basel); Remo Frei, PhD, (Christine Kühne-Center for Allergy Research and Education (CK-CARE), Davos; Swiss Institute of Allergy and Asthma Research (SIAF), University of Zurich, Davos); Caroline Roduit, MD (Children's Hospital, University of Zürich, Zürich);

The Netherlands: Gert Doekes, (Utrecht University, Institut for Risk Assessment Sciences (IRAS), Utrecht). 


\section{ACKNOWLEDGEMENTS}

We thank our study participants and their families for their participation. We thank Karine

Hugentobler (University of Basel Children's Hospital) for proofreading the manuscript. Furthermore, we thank the entire BILD cohort team (University of Basel Children's Hospital, Switzerland; Division of Respiratory Medicine, Department of Pediatrics, Inselspital, Bern University Hospital, University of Bern, Switzerland).

This article is protected by copyright. All rights reserved. 
Table 1. Association ${ }^{\text {a }}$ of $17 q 21$ genotype (addtive effect for risk allele) with respiratory symptoms and wheeze by breastfeeding

\section{Total}

Stratum by exposure

\begin{tabular}{cc}
\hline Weeks with & $\begin{array}{c}\text { Weeks without } \\
\text { breastfeeding }\end{array}$
\end{tabular}

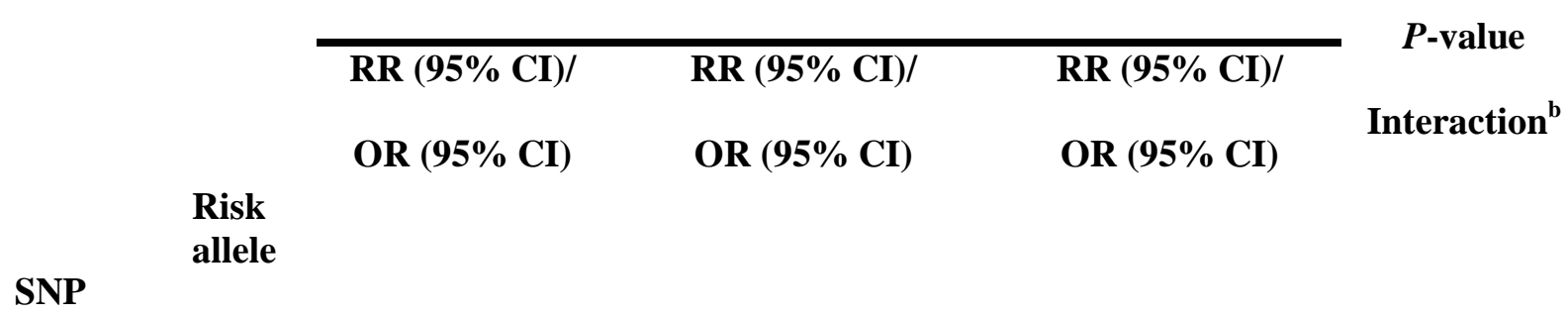

Discovery: BILD ( $\mathrm{n}=368$ and 252 for respiratory symptoms and wheeze, respectively)

\begin{tabular}{|c|c|c|c|c|c|}
\hline $\begin{array}{l}\text { Respiratory } \\
\text { symproms }^{d}\end{array}$ & $\begin{array}{l}\text { Respiratory } \\
\text { symproms }^{d}\end{array}$ & 19,252 & \multicolumn{3}{|c|}{6,741} \\
\hline rs7216389 & $\mathrm{T}$ & $0.98(0.90-1.08)$ & $0.82(0.72-0.93)$ & $1.09(0.96-1.24)$ & 0.0006 \\
\hline rs4795405 & $\mathrm{C}$ & $1.03(0.94-1.12)$ & $0.85(0.74-0.97)$ & $1.10(0.97-1.24)$ & \multirow{2}{*}{$\begin{array}{r}\mathbf{0 . 0 0 4 1} \\
0.217\end{array}$} \\
\hline rs8079416 & $\mathrm{C}$ & $1.07(0.98-1.16)$ & $0.97(0.85-1.11)$ & $1.07(0.94-1.21)$ & \\
\hline rs8065126 & $\mathrm{C}$ & $1.10(1.01-1.21)$ & $1.01(0.88-1.15)$ & $1.12(0.98-1.26)$ & 0.125 \\
\hline $\begin{array}{l}\text { rs3902025 } \\
\text { Wheeze }^{e}\end{array}$ & $\mathrm{~T}$ & $1.10(1.00-1.10)$ & $1.01(0.88-1.16)$ & $1.12(0.98-1.27)$ & \multirow[t]{2}{*}{0.204} \\
\hline Wheeze $^{e}$ & & $\begin{array}{c}\text { No. of weeks= } \\
13,101\end{array}$ & 8,564 & $\begin{array}{c}\text { No. of weeks= } \\
4,537\end{array}$ & \\
\hline \multirow{2}{*}{$\begin{array}{l}\text { rs7216389 } \\
\text { rs4795405 }\end{array}$} & $\mathrm{T}$ & $0.91(0.67-1.22)$ & $0.65(0.39-1.09)$ & $1.12(0.76-1.67)$ & 0.052 \\
\hline & $\mathrm{C}$ & $0.90(0.67-1.22)$ & $0.59(0.34-1.02)$ & $1.17(0.79-1.73)$ & 0.020 \\
\hline \multirow{2}{*}{ rs8065126 } & $\mathrm{C}$ & $1.15(0.85-1.57)$ & $1.05(0.62-1.76)$ & $1.25(0.84-1.88)$ & 0.718 \\
\hline & $\mathrm{C}$ & $1.08(0.77-1.51)$ & $0.69(0.40-1.17)$ & $1.46(0.93-2.28)$ & 0.037 \\
\hline rs3902025 & $\mathrm{T}$ & $1.16(0.84-1.61)$ & $0.89(0.50-1.57)$ & $1.37(090-2.08)$ & 0.253 \\
\hline
\end{tabular}

Replication: PASTURE (n=799)

\begin{tabular}{lccc}
\hline Respiratory & No. of weeks $=$ & No. of weeks $=$ & No. of weeks= \\
symproms $^{e}$ & 31,691 & 14,734 & 16,957
\end{tabular}

This article is protected by copyright. All rights reserved. 


\begin{tabular}{lllllc}
\hline rs7216389 & T & $1.10(1.02-1.19)$ & $1.11(0.98-1.27)$ & $1.11(1.00-1.22)$ & 0.689 \\
\hline rs8076131 & A & $1.06(0.98-1.14)$ & $0.99(0.88-1.33)$ & $1.11(1.01-1.22)$ & 0.370
\end{tabular}

\begin{tabular}{lccccc}
\hline Wheeze $^{e}$ & & & & \\
& & & & \\
\hline rs7216389 & T & $1.10(0.95-1.26)$ & $1.03(0.81-1.31)$ & $1.15(0.97-1.36)$ & 0.799 \\
\hline rs8076131 & A & $1.12(0.97-1.29)$ & $0.95(0.74-1.20)$ & $\mathbf{1 . 2 4}(\mathbf{1 . 0 4 - 1 . 4 6 )}$ & 0.174
\end{tabular}

\footnotetext{
Abbreviations: BILD, Basel-Bern Infant Lung Development birth cohort; PASTURE, Protection against Allergy Study in Rural Environments birth cohort; OR, odds ratio; RR, risk ratio; CI, confidence interval.

a adjusted for sex, week of age, presence of older siblings, birth weight, gestational age, mode of delivery, child care, maternal education, maternal/parental atopy, maternal smoking in pregnancy, week of, and study centers. In the replication analysis the association was additionally adjusted for farm exposure.

${ }^{\mathrm{b}}$ Interaction was tested by adding the product between breastfeeding and corresponding SNP in the adjusted model.

${ }^{\mathrm{c}}$ Per-allele RR and 95\% CI derived from generalized additive mixed model with quasi-Poisson distribution.

${ }^{\mathrm{d}}$ Per-allele OR and 95\% CI derived from generalized additive mixed model with Binomial distribution.

Significant associations after Bonferroni correction are in boldface.
}

This article is protected by copyright. All rights reserved. 
Figure 1: Associations of breastfeeding with respiratory symptoms and wheeze in the BILD discovery cohort and in PASTURE replication cohort according to rs7216389 and rs4795405 (the proxy is rs8076131): (A) respiratory symptoms and rs7216389; (B) wheeze and rs7216389; (C) respiratory symptoms and rs4795405 (the proxy is rs8076131); (D) wheeze and rs4795405 (the proxy is rs8076131).

Associations ( ${ }^{*}$ Bonferroni-significance) were adjusted for sex, week of age, presence of older siblings, birth weight, gestational age, mode of delivery, child care, maternal education, maternal/parental atopy, maternal smoking in pregnancy, week of, and study centers. In the replication cohort the association was additionally adjusted for farm exposure. Results were expressed as a risk ratio (RR) for the association between respiratory symptoms score in the BILD cohort and as an odds ratio (OR) for other associations. All estimates are given with $95 \%$ confidence interval $(95 \% \mathrm{Cl})$.

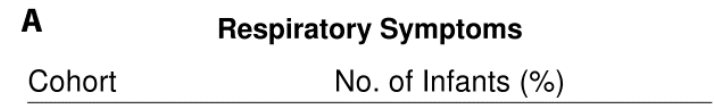

BILD: rs7216389

$\mathrm{C} / \mathrm{C}$

$\mathrm{C} / \mathrm{T}$

$\mathrm{T} / \mathrm{T}$

PASTURE: rs7216389

$\mathrm{C} / \mathrm{C}$

$\mathrm{C} / \mathrm{T}$

$\mathrm{T} / \mathrm{T}$

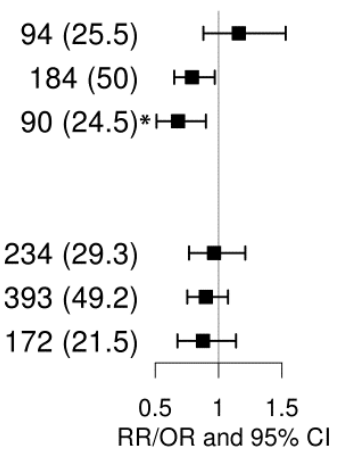

C

Respiratory Symptoms

Cohort

No. of Infants (\%)

BILD: rs4795405
T/T
T/C
C/C

PASTURE: rs8076131

$G / G$
$G / A$
$A / A$

$G / A$

$\mathrm{A} / \mathrm{A}$

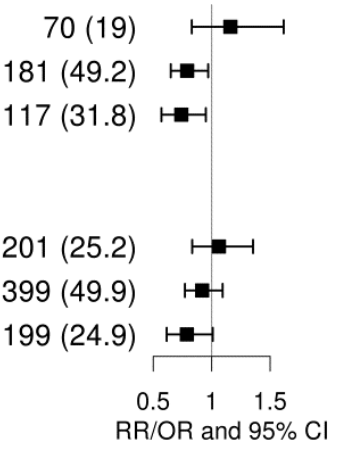

\begin{tabular}{ll} 
B & Wheeze \\
Cohort & No. of Infants (\%) \\
\hline
\end{tabular}

BILD: rs7216389

$\mathrm{C} / \mathrm{C}$

$\mathrm{C} / \mathrm{T}$

$\mathrm{T} / \mathrm{T}$

PASTURE: rs7216389

$\mathrm{C} / \mathrm{C}$

$\mathrm{C} / \mathrm{T}$

$\mathrm{T} / \mathrm{T}$

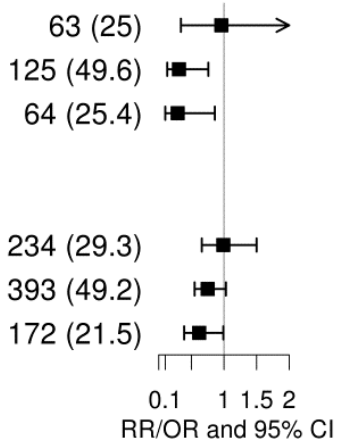

D

Cohort No. of Infants (\%)

BILD: rs4795405

$T / T$

$\mathrm{T} / \mathrm{C}$

$\mathrm{C} / \mathrm{C}$

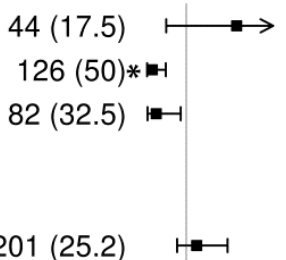

PASTURE: rs8076131

$\mathrm{G} / \mathrm{G}$

$\mathrm{G} / \mathrm{A}$

$\mathrm{A} / \mathrm{A}$

$399(49.9)$

$199(24.9) * 1$

9) $* 1=-1$

0.1123

$\mathrm{RR} / \mathrm{OR}$ and $95 \% \mathrm{Cl}$

This article is protected by copyright. All rights reserved. 